\title{
WARTIME PRICE CONTROL AND THE PROBLEM OF INFLATION
}

\author{
J. M. Clark*
}

\section{Inflation and the Normal Function of Price}

Everyone opposes "inflation"-or nearly everyone. And everyone agrees that war brings on inflation if it is allowed to run its natural course unresisted. But there is no real agreement as to just what "inflation" is. On the whole it seems best to consider that what we are talking about is harmful price increases of a widespread or general sort, and then go on to examine the things that do harm, and the kinds of harm they do; and forget this ill-defined and controversial term. So far as the term is used in this article, it will mean simply general price increases of harmful magnitude.

In ordinary times, it is customary to say, price is the agency which brings supply and demand into equality with one another, allocates productive resources between different products, determines how much of each shall be produced and limits demand to the amount that is available. This is a shorthand form of statement, and in some respects a bit misleading. The chief misleading implication is that production responds only to price; and, if supply is short of demand, production will not increase except as price rises. It is true that in such a situation price will usually rise, and production will increase; but this leaves out the most essential part of the process: namely, an increase in the volume of buying orders. In a large-scale manufacturing industry, this alone will ordinarily result in increased output. Both the increased production and the increase in price (if the latter occurs) are the result of the increased volume of orders. Price may not increase immediately, or at all; though it is likely to, since the pressure of competition on price will be reduced. It is more correct, then, to say that under ordinary circumstances production is governed by the volume of the buyers' demand, unregulated except by price, and by the willingness of the producers to supply the goods demanded, at the price that can be got.

The main regulator of the price factor in this combination of forces is the competi-

* A.B., 1905, L.H.D., I935, Amherst College; A.M., r906, Ph.D., rgro, Columbia University. Professor of Economics, Columbia University, since 1926; Consultant, Office of Price Administration, since 1940. Consultant to National Planning Board, 1934; Special Adviser, National Recovery Administration, 1934-35; member, United States Committee of Industrial Analysis, 1936-37. Author: Economics of Overhead Costs (1923); Social Control of Business (1926), Strategic Factors in Business Cycles (1934); Economics of Planning Public Works (1935); Preface to Social Economics (1937); and other works.

Views herein expressed are the personal views of the author and do not necessarily represent those of the Office of Price Administration. 
tion of the producers with one another; though where this does not work properly, for reasons unavoidably rooted in the nature of the industry, prices may be regulated. If the demand for a competitive product increases, profits and possibly-prices will increase, but not inordinately and not for long, because they will so promptly stimulate an increased output. The successful operation of the free-market regulators depends on the flexibility of production and productive capacity, relative to the shifts that are called for. If production is highly flexible, or if only moderate movements are called for, these movements may be engineered with only moderate incentives in the way of profit or loss, and without throwing the whole scheme of values into confusion. Under these conditions, profits and losses are accomplishing something that needs to be done, and are doing it at a moderate cost.

The serviceability of the market mechanism is clearest where it is a case of particular movements in a limited number of products. Where general movements are concerned, the operation of the mechanism is not so simple, and its serviceability is much more doubtful. In fact, economists are pretty well agreed that large and sudden general upward and downward movements in the price structure, which are regularly connected with general expansions and contractions of production, are regularly harmful. This is partly because the alternations of booms and depressions with which they are connected are not healthy features of our economy; and partly because they create injustices between different groups. A dollar with shrinking purchasing-power robs creditors and fixed-income groups generally, and has in the past proverbially fattened profits at the expense of wage-earners, since wages have regularly lagged behind the rise of prices. Under present conditions, with labor organization more widespread and stronger than ever before, this last feature is not observable; but there remains a discrepancy between workers who are in a position to secure an adequate increase in wages promptly, and those who are not.

To sum up, then, the general presumption in favor of unregulated price movements does not automatically apply to the kind and degree of increase which tends to result from an all-out military mobilization of the economy. What remains is the fact that authoritative controls are clumsy and difficult to manage, and produce widely-ramifying effects, many of which are difficult to foresee and handle. They also require substitute methods of stimulating or restricting supply, restricting demand where necessary, and allocating scarce supplies between conflicting demands. In this sense the "law of demand and supply" still has to be reckoned with. But the country has a standard of values, based on the vital requirements of war, which does not depend on demand as expressed by orders, at a price, in the markets; and it has ways of making these values effective without either ignoring price or acquiescing in the course which unregulated markets would take.

\section{Armament Drive Without Controls}

The normal effect of an armament drive is compounded of several elements. First is the direct demand for weapons of war, with the accompanying derived 
demand for labor, materials and productive equipment. Second is the methods used in financing the necessary outlays. Third is the reaction of the whole on the private demand for ordinary civilian products, and on the available supplies of these products. Fourth is the reaction of the market mechanism itself to disturbed conditions and anticipated changes, including speculation, inventory accumulation and hoarding. Underlying the whole are likely to be disruptions of normal supply lines for a large number of imported commodities.

The direct demand for war munitions calls, in the first place, for many things the country is not equipped to produce, such as ships, tanks and war-purpose airplanes in enormous quantities. Here we encounter the drawbacks of the mass production which has been the key to our industrial efficiency; for our plants are characteristically equipped with highly specialized machinery, suited to doing one thing and turning out one product or working on materials of a limited range of size and composition. So plants must be re-tooled or new plants built, and this may take a year or more. Ultimately, production will be huge, but, in the meantime, possibilities of increasing output are severely limited. First comes a more-thancapacity demand on the facilities to produce machines, and to produce the machinesto-produce-machines. Machine tools become the first bottleneck, and one of the sharpest.

Demand soon begins to make heavy drains on the basic materials, including lumber for army camps, a wide assortment of metals, and some chemicals. Shortages come in sight, but are hard to predict, partly because the program is a rapidly growing thing, and partly because its effect on civilian demand is uncertain. The problem arises of increasing capacity for the production of these basic materials. If we had known, when France fell, all that we know now, we should undoubtedly have undertaken at once the construction of such increased capacities in a number of materials, shortages of which are now necessitating the curtailment of civilian production. But producers were reluctant to gamble heavily in this direction, feeling sure that they would be left, after a few years, with excess capacity on their hands, and facing all the ills which this brings with it. Some expansion was undertaken; but, in terms of the demands now revealed, it was insufficient.

The basic characteristic of this situation is that demand for many things comes to exceed the supply that can be made available within a considerable period of time; and the dominant demand is of a peculiarly insistent sort. Government must have vital munitions, and will not be deterred by high prices. It will spend as fast as the supplies can be obtained, borrowing the funds if it does not possess them. Under such circumstances, prices cannot be trusted to rise merely enough to stimulate increased production; they can easily go far beyond the maximum amount that serves any substantially useful purpose of this sort. Even high-cost producers may make very large profits. The high prices serve to determine, among civilian wants, which shall be served; but they do not do this in any stable or useful fashion, largely because of the cumulative spirals which such a situation breeds. It does not lead to a stable 
equilibrium. And it may result in raising the prices of necessities of life, and thus create real hardship for those who have small incomes and cannot increase them.

Such an economic mobilization has two dimensions: the mobilization of management, labor, materials and productive equipment; and the mobilization of funds to pay for the resources used. From the standpoint of inflation, the problem may be described as one of maintaining a good working balance between these two dimensions, in order that monetary demand may not get too far out of touch with attainable supply. Of the two, the material resources are the critical thing-granted these, funds to move them can always be found, somehow. But from the standpoint of inflation it makes a great deal of difference how the funds are found, and we are learning much more about this than we suspected during the first World War. Material mobilization, under conditions such as ours in 1940, is a mixture of transfers of resources and increase of total output. Until the summer of I94r, it was possible to increase defense production and civilian production both at once. In a roughly corresponding way, financial mobilization is a mixture of transfers of dollar resources (taxes being the clearest case) and methods which increase the total amount of money funds or of active funds (expansionary borrowing). And one of the significant new things in the defense drive of I94I, so far as this country is concerned, was the growing recognition of the need for some kind of quantitative correlation between financial expansion and economic expansion.

On past occasions, the outcome has been a compromise between repugnance to heavy taxation and repugnance to heavy public debts. One side has urged putting the burden on future generations; the other has demonstrated that this cannot be done, because you cannot stop present enemies with shells which future generations are to make. The arguments have not met, because one bore on the fiscal burdens and the other on the physical ones; and neither bore on the quantitative question how far to go with each policy. The financial terms in which this question has customarily been argued appear to be largely obsolete, and others are finding their way into use.

The situation drives well-nigh irresistibly toward financial methods which put government's monetary demand into the markets without decreasing the total of civilian monetary demand, but more likely increasing it. Only a small-scale defense drive, or the early stages of a large one, can be financed in this way without encountering the limits of physical power to increase production as fast as monetary demand increases. The natural result is price-inflation.

The process begins with the materials on which armament makes the heaviest demands, relative to quickly available supplies. From these it spreads, by a process the details of which may vary according to conditions. Rising prices of basic materials affect the cost of producing goods in general, while demand increases through the spending by civilians of the increased money incomes received for defense work. Dealers bid to replace their stocks, and something more, and inventories grow, thus intensifying the increase in demand as it reaches the manufacturers and the producers of materials. To this is likely to be added a purely speculative demand, creating 
scarcities in advance of any real shortage. Wholesale prices rise, and this is reflected in retail prices after a lag of weeks or possibly months. If the public and the Government have a stern eye on prices, dealers are especially likely to postpone increases until goods bought at earlier and lower prices have been disposed of. But costs of living do rise.

At this point, if not earlier, there will be a general demand for higher wages to offset the cost of living. In the present instance the demand came earlier, and there was a fairly general round of wage increases in the spring of $194 \mathrm{I}$, in which the steel industry played a leading part, while the cost of living had not risen more than about $3 \%$. Many industries could absorb these wage increases out of the economies of increased output, but not all. And these economies reach an end and may be reversed as less skilled labor has to be employed, or overtime and night shifts worked. Ultimately, if the process is left to itself, a wage-price spiral appears, in which wages and the cost of living pursue one another and drive one another upward, with no easily assignable limit. Such a movement is clearly useless as a means of mobilizing resources for war needs, and in other respects is thoroughly harmful.

While prices are free to rise, profits are likely to increase, and such profits represent a reward for scarcity rather than for superior efficiency, and arouse more justified discontent than any other single feature of the situation. For a while, also, so long as munitions do not absorb more than the possible increase in total product, wageearners may have more to consume. A really all-out military effort, however, will not permit this; and then the attempt to maintain the workers' consumption by raising wages proportionally with the cost of living becomes largely self-defeating. If there are no more goods to be had, increased money incomes will not buy more, but will merely bid up prices if the money is spent, thus necessitating a further wage increase if the hopeless pursuit of parity between wages and cost of living is to be continued. The process tends to obstruct production by multiplying the occasions for strikes, as well as increasing the uncertainties which hamper the forward planning of business. Perhaps the worst sufferers are those who must live on fixed or relatively fixed incomes, for their dollars shrink without possibility of compensation.

Inflation also increases the dollar cost of arming. So far as this cost is supported by current taxes, the increase is mainly nominal, since the tax yields increase also, though perhaps not in quite the same proportion, and yields of income taxes will, of course, lag. As to outlays financed by borrowing, the fiscal effect hinges on the course of prices in the long run, after the emergency is over, and is only part of the larger effect which the post-emergency course of prices will have on the whole state of the economy. The most obviously probable outcome is the collapse of the inflated price-structure; and this will intensify the depression which is likely to follow, and increase all the difficulties of resuming an orderly course of economic life. Financially, it will leave the Government paying interest and principal, so far as it may repay principal, in more expensive dollars than it borrowed. There are other possible outcomes, but none is free from serious drawbacks and dangers. 
Possibly this incomplete sketch will serve to indicate the main evils of an uncontrolled price structure in time of war or a major emergency, and the reasons why a determined attempt at control is imperative. The experience of the first World War showed that controls can accomplish something, though in that case the attempt did not begin until the greater part of the inflation had already occurred, and it was too late to do more than set limits on the movement and bring a greater degree of order into the chaotic labor market. The principle of raising wages to match the rising cost of living was widely applied, while wages in numerous essential industries rose more than this. Thus average "real wages" rose, though it is doubtful if the real consumption of the workers did so.

As to prices, a rough gauge of the effectiveness of control is afforded by a comparison of the average prices of commodities which were at some time controlled, with those which were not. ${ }^{1}$ In round numbers, the controlled commodities had on the average about doubled in price at the time controls were instituted, while the uncontrolled group had risen roughly four-fifths as much. During controls, average prices of the controlled group were nearly stabilized, while those of the uncontrolled group gradually caught up. This average picture, for the controlled group, is probably less representative than most averages, since there were some prices which continued to rise markedly, and others which had already risen so far that it was possible to bring about very considerable reductions. Had controls been initiated much earlier, the total rise would undoubtedly have been less, but there would have been a substantial rise in the controlled group subsequent to the setting-up of controls. Applying this experience to our present situation, we have instituted controls soon enough to have considerable preventive effect; and if all elements of the program work together properly, we may hope to forestall any inflation-spiral comparable to that of the first World War; but it would be too much to expect that controlled prices should be permanently and completely stabilized. However, up to November, I94I, prices subject to formal "ceiling" orders, as distinct from informal controls, remained substantially stable.

\section{Objectives and the Factors that Condition Them}

The objectives of price policy in a national emergency may be inferred in a general way from the foregoing sketch of the evils we wish to avoid. But when it comes to making the objectives sufficiently specific to furnish guides in the actual doubtful decisions with which an administration is faced, we must consider them in the light of the conditions which determine how far it is possible to go and at what point one desirable objective may have to be sacrificed to another.

The primary objective, to which all forms of policy must contribute, is to secure the necessary munitions of war. We want to do this with as little disturbance to prices

\footnotetext{
${ }^{1}$ Fuller data can be found in Garrett, Government Control over Prices, War INdustries Bd. Price Burl. No. 3 ( 1920$)$, pp. 4I4-563. Many of the commodities in the "controlled" group were under actual controls only during the later months of the period covered; but informal pressures and the imminence of formal controls had some effect.
} 
as possible, but any price increase which is genuinely necessary must be allowed. Furthermore, one thing which must be kept very firmly in mind is that the amount of war material needed is not properly to be regarded as limited by any particular program or by the appropriations in force at any particular time, but solely by our ability to turn out the goods. The program has been increasing and will inevitably increase further. If, at any time, we find that we are fully living up to the program as it then stands, that is a sign that it is time to revise the program upward. Viewed in this light, there is simply no such thing as meeting the requirements of arming and also the full amount of civilian demands. The military program is inadequate unless it expands until civilian demands are interfered with at a good many points, and very materially.

With this proviso, then, we still want as much civilian production as is consistent with armament needs. We are going to be adequately fed, and with reasonably good management we ought to be better fed than usual in the past, from the standpoint of health. We are going to be adequately clothed, and, outside of centers congested by war work, we shall be as well housed as usual. But sharp curtailments have become necessary in consumers' durable goods which make heavy demands on the metals needed for ships, tanks and aeroplanes. And there will be shortages in other directions. At present, the limiting factor is mainly shortage of these key materials, and products which do not make heavy demands on them will continue to be produced even if nonessential. But the list of limited materials is growing.

A later stage may come at which we shall press against the ultimate limits of our man-power, and if this happens, we shall then not be able to afford labor for really nonessential products. At present, we are probably nearing this situation, and while it is really important that the production of nonessentials, which do not compete with defense, should continue (not so much because it is important for consumers to have these products, as because it is important for the workers who make them to have jobs) this situation will change as fast as the making of arms requires the labor now engaged in making otherwise noncompetitive nonessentials. The ideal of conversion to defense work without intervening unemployment, is not completely attainable. In some cases, temporary unemployment may be incidental to putting pressure on employers to use ingenuity and determination in solving the problems of conversion. The all-out war program has forced a more rigorous attack on this problem.

The limitations on production are of various sorts. In some cases we have reached the absolute limit of our productive capacity with existing facilities. This is not an absolute limit in the long run, but raises the question whether it is advisable to take the materials and labor which are necessary to enlarge the existing productive capacity. If the capacity is insufficient for military needs alone, there is no real question; but if it is merely a matter of failing to meet the full civilian demand, expanded as that is by a large flow of money income, then the question becomes more difficult.

Some products it may be possible to increase, but only by incurring abnormally 
high costs for all or a large part of the supply. Products which are wholly or largely imported are in this class, and here an increase in price is unavoidable. In other cases it may be only a small percentage of the product which is produced at abnormally high costs and which requires an abnormally high price to bring it into the market. In such a case a one-price policy would give large profits to most of the producers for the sake of securing an extra $2 \%$ or $5 \%$ of output. In such cases it is possible to secure the extra output without paying the high price for the whole supply, provided we are willing to undertake whatever administrative burdens and difficulties are involved in a differential-price system, or some other way of meeting the same difficulty. The present administration has from the start been prepared to take such measures, and is now employing them.

We are also in sight of some of the more general limitations on our power to produce. The problem of skilled labor is being met by a training program, though the problem of moving the labor to the places where the war work requires it, and of providing housing facilities, is not an easy one. Back of this lie limitations on the capacity of our transport system, and our capacity to produce electric power. Increasing the power supply, in particular, will require both large amounts of steel and large amounts of time; and in the meantime there is very likely to be a real shortage. The most general limitation, of course, is the limit on the supply of labor capable of being trained to the necessary skills and put to work in the essential industries. This limitation is an indefinite and an elastic one, and cannot be clearly measured by merely counting the number who are at present classified as unemployed. Some of these unemployed will not prove usable, but on the other hand many who are not ordinarily in the market for employment can be drawn upon in a real emergency. The ultimately available supply of labor is larger than the number ordinarily rated as "gainfully employed." Even at present, before all of the unemployed have been absorbed, we have begun to draw on this reserve of persons not normally in the labor market.

Another objective is to allocate scarce products and scarce productive resources to the most important uses. And for purpose of determining which are the most important, we shall not be satisfied to be governed by the test of willingness and ability to pay a price in an uncontrolled market. We face situations in which this would mean injuriously high prices, and those who can afford to pay them may not be those to whom the products are most important. This raises the question of administrative allocation or rationing.

One phase of this problem is the need of keeping enough of the real necessities within the reach of everyone. So far as we can now foresee there will be no real difficulty in doing this, so far as supply is concerned. It will be mainly a matter of preventing general and violent inflation of prices.

Another objective is the avoidance of so-called "profiteering." This has sometimes been expressed as an absolute determination that no one shall be allowed to make a profit out of his country's danger. Such a rigid formula sets an impossible standard. 
Producers will necessarily incur some uncertainties and some will come out better than others. If we actually see to it that those who come off best make no profit, others will inevitably take losses. There will be many differences in cost of production of products which will necessarily be sold at a standard price, since it will not be practicable to follow a universal policy of paying different prices to different producers for the same products. What is practicable is to see that prices are such that profits of arms production shall not be, on the average, much above normal levels, especially after deducting taxes, including an excess profits tax. Even the excess profits tax cannot usefully be so levied and administered as to take $100 \%$ of all profits above any determined level. There may be cases in which it will seem expedient to allow increased prices to do a good deal of the work of rationing scanty supplies. In such cases a specific excise tax on the particular commodity may solve the problem of permitting high prices without also permitting unearned profits.

Another obvious objective is to prevent the effect of actual shortages from being intensified by purely speculative activities, which may at times lead to useless hoarding, and may cause a shortage to arise merely because one is anticipated.

Two other matters on which real national objectives particularly need to be defined are farm prices and wages, which threaten to clash in an endless inflationary pursuit-race. To restrain inflation requires a resolution of this contest. ${ }^{2}$

The Price Control Act of January 30, I942, defines limits below which farm prices may not be forced by price-ceiling orders, either directly or via ceilings on products processed "in whole or substantial part from any agricultural commodity." This represents, not a national objective but a pressure-group objective, and is calculated to ensure progressive inflation. The more moderate standard of "parity," announced as an approximate guide to policy by the Secretary of Agriculture and the Price Administrator, depends for fulfilment on other measures than price-ceilings-chiefly, perhaps, on the release of stocks of grains and cotton.

As to wages, the Act instructs existing Government agencies dealing with wages "to work toward a stabilization of prices, fair and equitable wages, and cost of production." 4 This presents both a problem of reconciliation of objectives, and a problem of implementation. So far, compulsory wage ceilings have been considered both undesirable and impracticable, even under war conditions. To sum up, objectives in these two crucial fields depend on administrative definition and action, and the two have not been brought together in one formula.

\section{Methods of Price Control}

One of the soundest and most obvious methods of forestalling an increase in prices is to insure an adequate supply. The Government has been concerning itself with this matter in a number of ways. Where increased facilities were needed, one of the problems to be met has been the uncertainty as to how long the facilities

\footnotetext{
${ }^{2}$ Cf. J. M. Clark, Wages and Prices in All-Our War (Feb. 1942) 3i Surver Graphic 85.

${ }^{3}$ Pub. L. No. $42 x$, 77th Cong., $2 d$ Sess. (1942) $\$ 3$ (c).

'Id. $\$ \mathrm{r}(\mathrm{a})$.
} 
would be useful. In some cases it has been sufficient to allow the producer installing the facilities to include, for tax purposes, amortization charges on a five-year basis In more difficult cases, the Government has assumed the burden of furnishing capital. Another policy which has been followed has been the attempt by the Government to build up stock-piles of critical and strategic commodities. In some cases it has been possible to forestall purely speculative shortages by merely disclosing the facts as to existing supplies.

The most direct contact which the Government has with prices is in its own buying. Here one of the first requirements is a unified or co-ordinated purchasing system, under which different departments, and allied purchasing authorities, will not be working at cross purposes and bidding against one another. The most usual method of public purchase is by competitive bidding, but this has severe limitations in a national emergency. It makes an efficient distribution of orders difficult; and the lowest bidder is by no means sure to be the one to whom the order should go, in the light of the amount of business he already has and the labor situation which may result from his securing the order, or failing to secure it. For war mobilization, it is practically necessary to rely to a large extent on directly negotiated prices. These prices may be fixed by contract, with or without provisions for adjustments in case of certain kinds of changes in cost. In some cases it is practically necessary to make contracts on the basis of cost plus a certain margin. The crude form used in the first World War-cost plus a percentage of cost-has been discarded in favor of cost plus a fixed margin, which may be a percentage of an estimated standard cost, determined in the contract.

Government buying, however, for the most part, does not directly affect prices of things which are dealt in in the general market, though it may influence the price of basic materials. For such things, direct governmental control must take the form of determining the price which private individuals will have to pay. Within this field there are various broad divisions, which require different treatment, and which may expediently be handled by different agencies. In the first World War, for example, the Price Fixing Committee of the War Industries Board concerned itself with basic materials while there was a distinct food administration and a fuel administration, and rentals were handled by local committees.

Control of basic materials sold to producers raises one set of problems, while control of finished consumers goods, especially at retail, raises a different set of problems. In the case of basic materials the control is easiest where there are fewest producers to deal with; in short, where the situation is least fully competitive. The markets for scrap metals have been harder to control than the prices charged for the same metals by primary producers.

Finished consumers' goods are not only vastly more numerous than the basic materials, but involve baffling complexities in the matter of quality. This question becomes peculiarly difficult at a time when war-created shortages require a great many substitutions for customary materials, and it becomes necessary to determine 
whether these involve a deterioration of quality against which the consumer should be protected, or an evasion of measures of price control. Control of prices without some control of quality is fatally incomplete, yet control of quality throughout the entire field of consumers' goods is an administrative impossibility. Something may be done, as was done by the Food Administration during the first World War, in the way of control of producers' margins, but this in turn is complex and difficult, and cannot secure very precise results. It seems clear that direct control of price can operate only with reduced precision and increased difficulty, outside a somewhat limited field.

The standards appropriate to this kind of control are decidedly different from those which have been used in the past in the control of public utility rates. Prices will apply to a number of different producers, often a very large number, and it is a commonplace that there are always some producers who are losing money, at any price the market may set. There is not much danger that prices will be set so low that large and efficient producers will not make a "fair profit." The necessity of bringing into the market some higher-cost producers will ordinarily take care of that. The real question is one of fixing a price which will bring in the needed supply; and for the higher-cost producers the decisive question will be whether they can earn anything above operating expenses. If so, they will be doing as well as competition ordinarily permits the higher-cost producers to do.

One way of approaching this kind of price-fixing is to fix the price at the level which prevailed on some actual date, selecting a date when the price was clearly sufficient to bring out the needed production. This will be virtually certain to yield better returns than competition affords on the average of good and bad times.

There are many specific problems, too numerous to go into in detail. One is the problem of whether it will be sufficient to fix the price of a few key types or grades of a particular commodity, and trust the other types and grades to be priced in reasonable harmony, or whether it will be necessary to make completely comprehensive price schedules covering all types and grades, or all differentials from basic prices. Dealers' margins also present their own peculiar problems. It is sometimes necessary to see to it that the dealer does not evade a price order by requiring the purchaser to take also a certain quantity of some other product or products the price of which has not been controlled.

The most troublesome problem probably arises from the fact that demand will exceed supply at the prices fixed, and some form of allocation or rationing will become necessary. This is difficult enough where only sales to producers are concerned. To be really effective, it requires not merely the assigning of a rating to a given producer's requirements of materials for a given product, but a time schedule of deliveries to which the rating applies. But the scarcity of materials for producers is only a reflection of a coming scarcity of their finished products, and raises the question of allocation or rationing to the final consumer. In some of the milder cases it may be sufficient to allocate supplies to the dealers, and to leave it to the dealers to make them go around among their customers-as was done, briefly, with gasoline. Where this will not work, the Government may try rules limiting the amount that may be 
purchased at any one time, but it is hard to prevent consumers from merely buying oftener, or buying from more than one dealer. The only really positive system is that of ration-cards: now about to be issued for sugar.

The most ambitious proposal for direct price controls has been made by $\mathrm{Mr}$. Bernard M. Baruch, and represents the outgrowth of his experience as head of the War Industries Board during the first World War, and his attempt to cure the shortcomings revealed by that experience. ${ }^{5}$ These were the shortcomings attendant on piecemeal methods of control, which could not attend to everything at once, and had no effective means of controlling many elements of cost. The proposal is for a comprehensive ceiling over all elements of the price system, including wages, interest, commissions and all forms of payment for services. The ceiling would be fixed at the levels prevailing at some given date: presumably one at which prices were still in a fairly "normal" relation to one another, though it would be likely to be installed after prices of essential defense products had risen sufficiently to afford some stimulus to increased production. These ceilings would be subject to revision upward for any single product or service on showing of necessity (or downward if the ceiling proved too high in any case). Thus the effect would be, not to prevent all change, but to require positive action to change any price ceiling. Mr. Baruch's expectation was that fewer specific price determinations would be required than under the system of piecemeal regulation. Movements of prices below the ceilings would be free of formal obstacles. The problem of high prices for imported products was met by the proposal for an export-import pool, which would lose money on imports, sold at domestic ceiling prices, but would make offsetting profits on exports. Fiscal and credit measures were also contemplated, operating to reduce excessive purchasing power in the hands of the general public, and thus to reduce pressures which might tend to break through the ceilings.

The basic principle of this plan deserves serious consideration, especially since a fairly close approach to it was put into effect by Canada in December, and has revealed no serious weaknesses during its first month and more of operation. The plan appears suited to deal with a specially urgent crisis, if business and labor can be convinced of the need for it and will give it united and sincere support. . It will tend to be converted sooner or later into a comprehensive system of specific controls, via piecemeal revisions, but meanwhile it may render important service by holding the price structure, when it would otherwise get out of hand before the coverage of specific controls could be sufficiently expanded.

The success of this plan appears to hinge mainly on the practicability of establishing sufficiently full coverage, and to this there are great obstacles. Without labor's support, wage ceilings would surely fail. Even under a wage ceiling, wage costs would rise under the system of time-and-a-half for overtime; and premiums would probably be necessary to attract sufficient labor into some essential occupations. Opportunities for evasion would be many, including promotions and upgrading, paying

\footnotetext{
${ }^{5}$ His most recent statement was his testimony on the Price Control Bill. See Hearings before the House Committee on Banking and Currency on H.R. 5479, 77th Cong., xst Sess. (Sept. 19, 194x) 989-1045.
} 
learners at full rates, new designations of jobs, and other devices, some of which might be necessary and legitimate.

Unstandardized products would furnish another difficulty, especially work regularly done to special order or on contract, as in the case of construction work. Substitutions of materials, necessary or otherwise, and changed models of products, would require special action. Moreover, quoted prices include a surprising number of stipulations as to terms of delivery and settlement, which it might not be desirable to standardize yet which, if not standardized, might leave room for changes equivalent to an increase in price. Local differentials would often need to be adjustable, and representative past differentials may not suit existing conditions. Products whose prices move in seasonal cycles would afford a special group of problems.

Finally, while a blanket ceiling may be gradually converted into specific price orders, for many products, there appear to be areas that we can hardly expect to reach successfully in this way. In such areas, a blanket ceiling may have some effect, but inflation can hardly be prevented unless the inflationary pressures themselves can be limited.

This brings us to the last main group of measures tending to limit prices: namely, those which limit the flow of purchasing power which private buyers have available to spend. Increased government spending puts more money in the hands of private individuals, and increases their spendings also. Until midsummer of $194 \mathrm{I}$, these increased spendings have called forth increased supplies; not fully proportionate to the increased spending, but still substantial. Now, with new munitions plants getting to the stage of quantity production, their demands for materials, especially metals, are necessitating sharp curtailments in the field of consumers' durable goods, and there is doubt to what extent this will be offset by increased physical volume of purchases in other fields, which are still free to expand without conflicting with armament.

The excess of income above supply of things to spend it on will increase-of that there can be little doubt. If spent, it will bid up prices by a truly mathematical necessity. If this is not desirable, then the excess income may be taxed away or borrowed away. It is not likely for long to lie idle, in amounts beyond a normal relation to income. Thus we arrive at the idea of preventing price inflation by levying taxes or floating loans intended to absorb private funds that would otherwise be spent. This is one conscious aim of our present fiscal policy, and accounts, among other things, for the issuance of nontransferable defense savings bonds; in contrast to the policy adopted during thet first World War, of urging subscribers to "borrow and buy," with the bonds themselves as collateral.

Space will not permit any extended discussion of the problems of taxation as affected by the attempt to graft this new objective onto the other objectives which have customarily governed tax policy. From this standpoint, taxation of the really generous incomes is of little effect, since it is likely to come mostly out of savings rather than out of consumption. It may actually have an inflationary effect if it reduces free savings below the requirements of capital expansion, and forces business to Borrow from the banks. Increased taxation of incomes in the $\$ 5,000$ to $\$ 10,000$ range 
will have a mixed effect, and the total effect on consumption to be expected from it is not very large. Taxation must reach the really modest incomes in order to bring about really material limitation of consumption expenditures. And there is a perfectly natural reluctance to lay really heavy burdens in this quarter, in the form of ordinary taxes. As the war effort expands, it is doubtful if any practicable tax program can wholly remove its inflationary effects.

Excise taxes are an ambiguous feature of such a program. They absorb the consumer's purchasing power; but, since he pays the tax with the price of the goods, it is a little less than obvious how it serves as a remedy for price inflation. Of course, it would be possible to legislate that the "price" of the taxed commodity should be defined as not including the tax, if juggling with terms would help. But there is a real and substantial difference between excise taxation and price inflation, in that true price inflation is cumulative, and the money represented by a price increase continues to circulate in the markets, while excise taxation does remove the money from circulation, and thus does really reduce excess purchasing power. ${ }^{6}$ There is the further question whether this might be the occasion for wage demands to offset the increased amounts the purchaser has to pay for goods; but it seems probable that any form of taxation falling unmistakably on wage earners would be about equally likely to have this effect. ${ }^{7}$ If the country can succeed in establishing the national wage policy which is so badly needed, one rational feature would be the general principle that in any wage adjustments aiming to offset increased costs of living, taxes are not a proper element to take into account. Otherwise the anti-inflationary effects of taxation could be largely nullified in one of the largest and most important sectors of consumption; and the possibility of using this instrument for preventing the evils of inflation would be seriously and perhaps fatally crippled.

The most important feature of excise taxation is its selective character, in contrast to income taxation, which can only reduce purchasing power in general, without doing anything to direct it away from those commodities, supplies of which have had to be curtailed, or toward those commodities and services in which expansion may still be possible. Excise taxation permits the short supplies to be rationed by a calculated increase in the gross price the consumer has to pay, where that may seem the most practicable method, without permitting the producer to pocket the increase as an unearned profit and to start it circulating through the markets as an added inflationary increase in the money flow. In this form price becomes a legitimately usable instrument for rationing shortages. This is important, since not only is direct consumer rationing a thing to avoid unless necessary, but the durable goods, in which the acute shortages are occurring, present peculiar difficulties. It is hardly practicable to tell the would-be buyer of a new automobile or refrigerator that he can have only

\footnotetext{
' Of course, the Government will spend the money it gets in taxes. But if it had not collected the taxes, it would have spent just as much, and private individuals would have more available to spend. Some of them might lend part of it to the Government (which would have to borrow what it did not collect in taxes), but they are morally certain to lend only a minor part. Most of the public borrowing thus occasioned would presumably come out of credit expansion.

${ }^{7}$ Cf. statement of Philip Murray, President of C. I. O., including personal taxes in the "cost of living" for which wage increases should be demanded. N. Y. Times, Jan. 27, 1942, p. I5.
} 
half of one; and the difficulties of deciding who shall be allowed to have one, and who shall not, are obvious. However, curtailment of durable goods has suddenly become so drastic that excise taxes are in most cases likely to be inadequate.

Restrictions on credit, like taxation, may be selective or nonselective. An increase in reserve requirements is nonselective, though banks affected by it might follow selective policies in restricting their loans. The most naturally selective instrument in this field is instalment credit, which is obviously one of the most powerful factors affecting demand for just those durable goods which present the most acute problems. The great increase in purchases of automobiles and mechanical household equipment, which took place up to midsummer of $194 \mathrm{I}$, was facilitated by a corresponding increase in the volume of instalment credit outstanding. Moderate limitations on instalment credit have been instituted, and can be developed into really effective restrictions on the demand for durable goods, where shortage is not too extreme.

The present policy of voluntary loans from individuals is entirely appropriate, but it will be effective as a remedy for inflation only to the extent that the individuals lend the Government funds they would otherwise have spent. If, as is likely, many of them merely invest with the Government funds they would have saved in any case, there is no reduction of inflationary spending. Ultimately, it appears that more positive measures in this direction will be called for, if inflation is to be effectively checked. This has led to various proposals for "siphoning-off" present income and giving the individual a deferred claim. This claim may be made available for him to spend at some future time when he may need it more than he does at present, and when the economic system may need the stimulus of added spending, as it does not need it now, to keep going at a fairly full rate of operation and to maintain employment. Extensions of the social security system have been suggested as one way of accomplishing this. Or it has been suggested that wage increases should take the form of government bonds rather than cash.

Among economists, there is general agreement that rising prices need to be combated not only by direct price controls but also by restricting wage increases and by fiscal and credit measures aimed to limit purchasing power. But there is some disagreement as to the relative emphasis to be placed on the several types of measures, and particularly as between direct controls and controls operating through purchasing power. Until recent months, some were reluctant to limit purchasing power heavily for fear that, if controls were strict enough to set effective limits on prices, they would also shut off some physical production of things that might be had without conflicting with defense. With the growth of the armament program, this fear has become groundless. The utmost practicable restriction of purchasing power will still leave inflationary pressures which will strain the machinery of direct price control and rationing.

Others see so clearly the difficulties and limitations of direct controls, especially perhaps the regimentation and rationing which it presupposes, that they are inclined to go to the other extreme, and place main reliance on measures acting through purchasing power. The fact seems to be that there is no chance of succeeding in 
preventing very serious price increases unless both types of measures are used to the fullest extent. This calls for more powerful direct price controls than have been available to the Price Administration prior to the recent Price Control Act, and also heavier taxation than is yet embodied in proposed tax bills. They must both be used until they hurt. This implies that a man will feel hurt if some of his money income is taken away from him, because he feels that this reduces the amount of goods he can buy, even though the feeling may be wholly an illusion, because the amount of goods is limited by the needs of defense, and the consumer will be able to buy just as much with a smaller cash income as with a larger one, if all consumers are treated alike.

In principle, the most rational division of labor between the two types of policy would seem to be to rely on direct controls and selective limitations on buying power in the areas of special scarcity, while imposing general limitations on purchasing power sufficient, if supplemented by informal pressures, to prevent serious increases of prices in the general field of miscellaneous consumer-products in which no special scarcity or bottleneck has arisen. This admittedly makes the problem simpler than it is in fact. But unless some such division of the field can be worked out, the policy of preventing runaway price increases will fail.

\section{Conclusion: General Problems}

One thing which should be clear is that the task of preventing runaway prices includes a number of major elements, the actual handling of which belongs in various existing branches of the Federal Government other than the Price Administration. It requires a coordinated achievement of teamwork. The Price Administration is suited to the direct control of prices, but fiscal and credit measures are outside its field, and so also are any policies which may be attempted in respect to wages. What is needed, then, is a national price policy in which the various cooperating agencies shall play their complementary parts. The need is greatest in the case of wages and farm prices.

Both in forming and administering policy, one of the most important things is to set objectives neither too high nor too low. Those in charge of the different branches of the program must not expect too much of the other branches, nor demand too little of themselves. Until recent developments, lack of formal powers has necessitated rather modest objectives. With the added legislative powers now granted, more may be attempted, and must be if the attempt is not to fail; but it will still depend to a large extent on willing compliance by the majority of those affected. Courage and determination are needed.

Mistakes will inevitably be made. But mistakes can and will be rectified. What is most needed is general recognition that the emergency is serious, and that the dangers of uncontrolled inflation are more serious to all concerned than the burdens which control will inevitably lay on particular groups. Some general increase in prices appears bound to occur, even if a blanket ceiling is adopted and is reasonably successful. To prevent it from becoming disastrously great will require loyal and understanding support from all sectors of the nation. 